Rev. Bras. Saúde Prod. Anim., Salvador, v.15, n.4, p.1052-1060 out./dez., 2014 http://www.rbspa.ufba.br ISSN 15199940

\title{
Desempenho e características da carcaça de novilhos submetidos à suplementação na seca
}

Performance and carcass traits of steers submitted to supplementation in the dry season

\author{
DOMINGUES, Miguel Sales ${ }^{1}$; LUPATINI, Gelci Carlos²*; ANDRIGHETTO, \\ Cristiana $^{2}$; ARAÚJO, Laura Costa Alves de ${ }^{2}$; CARDASSI, Marianna Rosa ${ }^{2}$; POLLI, \\ Daniel $^{2}$; MEDEIROS, Saulo Flaviano ${ }^{2}$; FONSECA, Ricardo da ${ }^{2}$; SANTOS, Juliana \\ Aparecida Alves dos ${ }^{2}$
}

\footnotetext{
${ }^{1}$ Universidade Estadual Paulista, Programa de Pós-Graduação em Ciência e Tecnologia Animal, Ilha Solteira, São Paulo, Brasil.

${ }^{2}$ Universidade Estadual Paulista, Campus de Dracena, Dracena, São Paulo, Brasil.

*Endereço para correspondência: lupatini@dracena.unesp.br
}

\section{RESUMO}

Objetivou-se com este trabalho avaliar o efeito de duas estratégias de suplementação no período seco sobre o desempenho e características da carcaça de novilhos terminados em capimmarandu. Foram utilizados 36 bovinos Nelore, machos, castrados, com peso inicial de 417 $\pm 10,7 \mathrm{~kg}$ e idade média de 20 meses. O delineamento experimental foi inteiramente casualizado com dois tratamentos e dezoito repetições. Os tratamentos foram constituídos de sal mineral proteinado (SMP) fornecido ad libitum e da suplementação com concentrado (SC) com $0,5 \%$ do peso corporal (PC). Após abate, as carcaças foram pesadas, identificadas e resfriadas por 24 horas. Foram medidos rendimento de carcaça, área de olho de lombo, espessura de gordura subcutânea, $\mathrm{pH}$ e escore de marmorização. Os animais da SC apresentaram maior $(\mathrm{P}=0,00007)$ ganho de peso médio diário $(0,562 \mathrm{~kg})$ e espessura de gordura subcutânea ajustada para $100 \mathrm{~kg}$ de carcaça $(1,7 \mathrm{~mm})$ em relação aos animais do SMP $(0,395 \mathrm{~kg} ; 1,3 \mathrm{~mm})$, respectivamente, mas não diferiram $(\mathrm{P}>0,01)$ em relação ao peso de carcaça, rendimento de carcaça, área de olho de lombo, pH e marmorização. Conclui-se que a suplementação com concentrado durante o período seco proporciona maior ganho de peso médio diário e espessura de gordura subcutânea ajustada para $100 \mathrm{~kg}$ de carcaça, antecipando a idade de abate e a utilização de sal mineral proteinado com massa de forragem adequada pode ser uma alternativa de suplementação devido menor exigência de estrutura, controle de consumo, menor mão-de-obra e maior facilidade no fornecimento.

Palavras-chave: área de olho de lombo, diferimento, Marandu, Urochloa brizantha

\section{SUMMARY}

The objective of this study was evaluate the effect of two supplementation strategies in the dry season on performance and carcass traits of steers finished on marandu grass. The experimental design was completely randomized with two treatments and eighteen repetitions per treatment. The treatments consisted of ad libitum protein mineral salt (PMS) and supplementation with concentrate (SC) with $0.5 \%$ of body weight. It was used 36 Nelore steers with initial weight of $417 \mathrm{~kg}$ and 20 months of age. After slaughter, carcasses were weighted, identified and cooled for 24 hours. Carcass yield, ribeye, fat thickness, $\mathrm{pH}$ and marbling score were measured. The animals supplemented with concentrate had higher $(\mathrm{P}<0.01)$ average daily weight gain $(0.562 \mathrm{~kg})$ and higher fat thickness adjusted to $100 \mathrm{~kg}$ carcass than animals supplemented with protein mineral salt $(0.395 \mathrm{~kg})$, but did not differed $(\mathrm{P}>0.01)$ in relation to carcass weight, carcass yield, ribeye, $\mathrm{pH}$ and marbling. The results show that the supplementation with concentrate accelerates gains, allowing early and better condition of slaughter and the use of 
protein mineral salt with adequate forage mass may be an alternative supplementation because less need for structure, control consumption, lower labor and greater ease in supply.

Keywords: deferring, Marandu, ribeye area, Urochloa brizantha

\section{INTRODUÇÃO}

A produção de bovinos de corte nacional é baseada em pastagens tropicais, tendo o gênero Urochloa grande representatividade com $85 \%$ das áreas de pastagens cultivadas (MOREIRA et al., 2011). O uso de pastagens como principal fonte de alimento para ruminantes é a alternativa mais econômica de alimentação dos rebanhos bovinos (MORAES et al., 2006), quando usada com manejo adequado e de forma sustentável. A intensificação da produção de gado de corte implica, entre outros fatores, em acelerar o crescimento e a terminação dos bovinos, de modo a promover o abate em idade cada vez mais precoce. Assim, a manutenção da curva de crescimento de bovinos em fase de recria a níveis ascendentes, e de forma contínua, constitui meta principal e determinante da eficiência produtiva (MORAES et al., 2006). O principal fator limitante é a variação crítica na produção e qualidade da pastagem ao longo do ano. Na época das águas, verifica-se alta produção de forragem com qualidade, enquanto que, durante a época da seca, observam-se limitações quanti-qualitativas no pasto (FERNANDES et al., 2010).

Entre as alternativas para equilibrar a estacionalidade da produção forrageira, a utilização de pasto diferido tem se mostrado promissor, por ser de baixo custo e de fácil adoção, e consiste em selecionar determinadas áreas de pasto e vedá-las ao acesso dos animais, no fim do verão. Dessa forma, é possível reservar o excesso de forragem produzida no período das águas para pastejo direto durante o período de escassez (EUCLIDES et al., 2007). Entretanto, no período de escassez a forragem apresenta baixa qualidade e a suplementação proteica e/ou energética auxilia na correção desta deficiência.

O uso da suplementação na produção de bovinos de corte se torna uma alternativa viável, a qual promove disponibilidade de nutrientes por meio de uma dieta equilibrada, permitindo o aumento do crescimento e engorda dos bovinos, melhorando o ganho de peso dos animais e tendo grande impacto sobre a eficiência da produção e redução da idade ao abate.

Neste contexto, o objetivo com esta pesquisa foi avaliar a utilização de suplementação com sal mineral proteinado e concentrado sobre $\mathrm{o}$ desempenho e características quantitativas e qualitativas da carcaça de bovinos de corte, recriados e engordados em pastagem de Urochloa brizantha cv. Marandu.

\section{MATERIAL E MÉTODOS}

O experimento foi realizado em fazenda localizada no município de Piquerobi, região oeste do Estado de São Paulo. O clima predominante na região é do tipo Aw, tropical chuvoso com inverno seco e mês mais frio com temperatura média superior a $18^{\circ} \mathrm{C}$. Os dados climáticos (Tabela 1) referentes ao período experimental foram coletados na estação meteorológica da Universidade do Oeste Paulista, situada na região. 
Rev. Bras. Saúde Prod. Anim., Salvador, v.15, n.4, p.1052-1060 out./dez., 2014 http://www.rbspa.ufba.br ISSN 15199940

Tabela 1. Dados climáticos referentes ao período experimental (março a novembro de 2008)

\begin{tabular}{lccc}
\hline Mês & $\begin{array}{c}\text { Temperatura } \\
\text { mínima }\left({ }^{\circ} \mathrm{C}\right)\end{array}$ & $\begin{array}{c}\text { Temperatura } \\
\text { média }\left({ }^{\circ} \mathrm{C}\right)\end{array}$ & $\begin{array}{c}\text { Precipitação } \\
(\mathrm{mm})\end{array}$ \\
\hline Março & 21,0 & 25,7 & 279 \\
Abril & 19,7 & 24,9 & 160 \\
Maio & 16,1 & 21,4 & 88 \\
Junho & 15,3 & 20,9 & 23 \\
Julho & 16,3 & 22,5 & 0 \\
Agosto & 17,2 & 22,2 & 94 \\
Setembro & 15,7 & 22,7 & 35 \\
Outubro & 20,8 & 26,6 & 177 \\
Novembro & 19,9 & 25,7 & 146 \\
\hline Média/Total - 9 meses & 18,0 & 23,6 & 1002 \\
\hline
\end{tabular}

Fonte: Universidade do Oeste Paulista, 2009.

Foram utilizados 36 animais (machos castrados) da raça Nelore oriundos do rebanho da Fazenda, com peso inicial de $417 \pm 10,7 \mathrm{~kg}$, idade média inicial de 20 meses, divididos em dois lotes de 18 animais, mantidos separados em piquetes de 19 hectares cada. A pastagem utilizada foi Urochloa brizantha (Syn. Brachiaria brizantha) cv. Marandu, diferida por 137 dias antes do início do experimento e com produtividade de massa seca semelhante entre os piquetes.

Os animais foram distribuídos em dois tratamentos, sendo sal mineral proteinado (SMP) e suplementação com concentrado (SC). O SMP foi fornecido ad libitum e a SC diariamente às $13 \mathrm{~h}$ na proporção de $0,5 \%$ do PC na matéria seca. Os bovinos foram identificados com marcas a ferro quente, realizado o controle parasitário com endectocida à base de ivermectina (1\%) e distribuídos nos tratamentos, adotando-se o critério de peso corporal inicial.

O sal mineral proteinado (Potenseca 40®) foi formulado com $40 \%$ de proteína bruta (PB), 34,3\% de nitrogênio não proteico (NNP equivalente proteína), 40,61\% de nutrientes digestíveis totais (NDT) e a seguinte composição mineral por kg: $50 \mathrm{~g}$ $\mathrm{Ca}, 25 \mathrm{~g} \mathrm{P}, 10 \mathrm{~g} \mathrm{~S}, 5 \mathrm{~g} \mathrm{Mg}$ e $62 \mathrm{~g} \mathrm{Na}$. O suplemento concentrado apresentou a seguinte composição: $47,80 \%$ milho grão moído, 39,90\% casca de soja, $6,65 \%$ farelo de soja, $2,70 \%$ sal mineral, $0,79 \%$ sal comum, $0,21 \%$ sulfato de amônio, $1,87 \%$ ureia e $0,08 \%$ rumensin, com $18,27 \%$ de $\mathrm{PB}, 5,85 \%$ de NNP equivalente proteína e 75,35\% de NDT. $\mathrm{O}$ período de adaptação ao SMP e à SC foi de 20 dias, com aumento gradativo da quantidade de suplemento. O SMP foi fornecido misturado ao sal mineral na proporção em $\mathrm{kg}$ de 1:2 na primeira semana, passando para 2:1 na segunda semana e depois somente o SMP. Na $\mathrm{SC}$ a quantidade fornecida foi de $1 \mathrm{e}$ $2 \mathrm{~kg} /$ animal/dia na primeira e segunda semana, respectivamente, e depois seguiu a proporção utilizada $(0,5 \%$ do $\mathrm{PC})$. Adotou-se o sistema contínuo de pastejo com lotação fixa de 1,0 animal/ha. Os suplementos foram fornecidos em cochos de plástico $(0,40 \mathrm{~m}$ linear/animal) e a água à vontade.

As amostras de forragem foram coletadas a cada 28 dias, uma semana antes da pesagem dos animais, utilizando-se 15 amostras de $0,5 \mathrm{~m}^{2}(0,5 \times 1,0 \mathrm{~m})$ em cada piquete, distribuídas aleatoriamente na área. A altura da pastagem foi medida nos locais das amostras por meio de uma régua graduada. A forragem coletada foi homogeneizada, pesada e posteriormente retirada três subamostras 
por piquete, as quais foram pesadas e levadas à estufa com circulação de ar forçada, para determinação da matéria seca (MS) a $65^{\circ} \mathrm{C}$. Outras três subamostras foram utilizadas para determinação da composição morfológica, sendo feita a separação manual dos seguintes componentes das plantas: lâmina foliar verde, lâmina foliar morta, caule verde e material morto.

A pesagem dos animais foi realizada a cada 28 dias, com jejum alimentar de 14 horas. O ganho de peso médio diário (GMD) foi obtido pela diferença entre peso final e inicial dos animais dividida pelo número de dias do período total. $\mathrm{O}$ peso de abate pré-estabelecido foi de $480 \mathrm{~kg}$. Os animais da SC foram abatidos com 123 dias de suplementação (período de 04/08/2008 a 05/12/2008) e os animais suplementados com SMP não chegaram ao peso de abate (em torno de $480 \mathrm{~kg}$ ) no mesmo período, permanecendo por mais 82 dias no pasto recebendo sal mineral. O SMP foi retirado dos animais no período de 05/12/2008 até o abate $(25 / 02 / 2009)$ e estes foram mantidos na pastagem e fornecido somente sal mineral (minerais $+\mathrm{NaCl}$ ), em função das precipitações (Tabela 1) no início da estação chuvosa e rebrota do pasto.

Os bovinos foram abatidos em frigorífico comercial após 14 horas de jejum. No abate, as carcaças foram identificadas e resfriadas por 24 horas em câmaras com temperatura de $0^{\circ} \mathrm{C}$. Após pesagem da carcaça foi calculado o percentual de rendimento da carcaça da seguinte maneira: $\mathrm{O}$ quociente entre o peso da carcaça quente e o peso corporal do animal antes do abate multiplicado por 100 .

Após o resfriamento foi mensurada a área de olho de lombo entre a $12^{\mathrm{a}}$ e $13^{\mathrm{a}}$ costelas através da régua de quadrantes de pontos e a espessura de gordura subcutânea, ambas segundo metodologia descrita pelo USDA (1997). Após realizadas as avaliações, foi calculada a espessura de gordura subcutânea e a área de olho de lombo ajustada para $100 \mathrm{~kg}$ de carcaça de acordo com o sugerido por Luchiari Filho (2000).

$\mathrm{O}$ pH foi determinado no músculo Longissimus, entre a $12^{\mathrm{a}}$ e $13^{\mathrm{a}}$ costelas, após 24 horas de resfriamento da carcaça. Para a determinação do escore de marmorização foi utilizada a metodologia descrita pelo USDA (1997), sendo os valores de 1 a 10 onde: $1=$ praticamente ausente, $2=$ traços, 3 $=$ leve, $4=$ pouco, $5=$ modesto, $6=$ moderado, 7 = levemente abundante, 8 $=$ moderadamente abundante, $9=$ abundante e $10=$ muito abundante.

$\mathrm{O}$ delineamento experimental foi inteiramente casualizado com dois tratamentos e dezoito repetições. Os dados foram submetidos às análises estatísticas utilizando $\mathrm{o}$ programa $\mathrm{R}$ para execução das análises de variância, e adotando-se o nível de significância de $1 \%$ de probabilidade.

\section{RESULTADOS E DISCUSSÃO}

$\mathrm{O}$ pasto apresentou elevada disponibilidade de massa seca total (Tabela 2), de massa seca verde e lâmina foliar verde na média, estando de acordo com Silva et al. (2009) que citam $4.500 \mathrm{~kg} / \mathrm{ha}$ de massa seca total e $1.200 \mathrm{~kg} / \mathrm{ha}$ de massa verde seca para garantir seletividade e ganhos individuais satisfatórios sem comprometer o ganho por área. Baroni et al. (2010) observaram que a oferta de forragem pode estar associada à digestibilidade de gramíneas tropicais, porque o animal seleciona as porções mais nutritivas (lâminas foliares verdes) em detrimento aos colmos e material senescente e explica em parte o bom 
Rev. Bras. Saúde Prod. Anim., Salvador, v.15, n.4, p.1052-1060 out./dez., 2014 http://www.rbspa.ufba.br ISSN 15199940

resultado em ganho de peso apresentado neste experimento.

Houve diferença $(\mathrm{P}=0,00007)$ no $\mathrm{GMD}$ entre as suplementações (Tabela 2), que foi de 0,395 e $0,562 \mathrm{~kg}$ para o SMP e $\mathrm{SC}$, respectivamente, sendo $42 \%$ maior para o último. Como consequência, os animais da SC foram abatidos antes, com peso final e acabamento compatível com as exigências do mercado, além da comercialização em período de preços mais elevados historicamente. $\mathrm{O}$ consumo médio do suplemento foi 0,320 e $2,5 \mathrm{~kg}$ para os tratamentos SMP e SC, respectivamente.

Tabela 2. Desempenho animal, consumo médio dos suplementos, peso médio inicial, massa e altura da pastagem

\begin{tabular}{lcc}
\hline Variável & Sal mineral proteinado & Suplementação com concentrado \\
\hline Ganho de peso médio diário $(\mathrm{kg})$ & $0,395^{\mathrm{b}}$ & $0,562^{\mathrm{a}}$ \\
Consumo de suplemento $(\mathrm{kg})$ & $0,320^{\mathrm{b}}$ & $2,500^{\mathrm{a}}$ \\
Massa total de forragem $(\mathrm{kg} / \mathrm{ha})$ & $5.286^{\mathrm{a}}$ & $5.646^{\mathrm{a}}$ \\
Massa seca verde $(\mathrm{kg} / \mathrm{ha})$ & $2.627^{\mathrm{a}}$ & $2.689^{\mathrm{a}}$ \\
Massa de lâmina foliar verde $(\mathrm{kg} / \mathrm{ha})$ & $1.156^{\mathrm{a}}$ & $1.092^{\mathrm{a}}$ \\
Altura da pastagem $(\mathrm{cm})$ & $31^{\mathrm{a}}$ & $34^{\mathrm{a}}$ \\
\hline
\end{tabular}

Médias seguidas de letras minúsculas distintas, na linha, diferem entre si pelo teste $\mathrm{F}(\mathrm{P}<0,01)$.

Utilizando os requerimentos diários para ganho de peso dos novilhos na SC $(0,667 \mathrm{~kg}$ PB e $5,656 \mathrm{~kg}$ NDT $)$ e no SMP $(0,653 \mathrm{~kg}$ PB e $5,067 \mathrm{~kg}$ NDT) obtido nos tratamentos de acordo com Lana (2007), verifica-se que a SC forneceu $29 \%$ do NDT e $60 \%$ da PB e o SMP forneceu apenas $3 \%$ do NDT e $20 \%$ da PB exigida pelos bovinos. Estes valores explicam em parte o maior GMD dos novilhos da SC, pois com uma maior ingestão de nutrientes do suplemento os requerimentos do animal em energia e proteína para um maior ganho de peso foram atendidos, os quais foram expressos no desempenho animal. Analisando os dados anteriores pode-se inferir que o nutriente limitante na dieta (pasto mais suplemento) para um maior GMD da SC foi o NDT, pois os animais em terminação exigem grande densidade energética na dieta e a pastagem no período seco apresenta baixo NDT. Moraes et al. (2006) afirmam que o diferimento da Urochloa brizantha durante a fase de crescimento resulta em produção de MS de baixa qualidade com alta proporção da fração indigestível (C) e baixa fração dos carboidratos potencialmente digestíveis (B2).

No SMP tanto a PB fornecida quanto o NDT foram limitantes para um maior GMD e foram menores quando comparados à $\mathrm{SC}$, tendo em vista que o fornecimento de $\mathrm{PB}$ via suplemento proteinado gerou apenas a manutenção dos níveis mínimos de amônia ruminal para desenvolvimento microbiano, o que possivelmente resultou no consumo de massa seca de forragem necessário para o desempenho obtido. Neste sentido, Oliveira et al. (2010) citam que o uso de suplementos proteicos contendo 30 a $40 \%$ de proteína bruta e fornecidos ao nível de $0,1 \%$ do peso corporal para bovinos consumindo forragem de baixo valor nutricional melhora os processos de digestão, por aumentar a degradabilidade efetiva da MS, da PB e da fibra detergente neutro (FDN) e por acelerar a taxa de 
passagem, reduzindo o tempo médio de retenção no rúmen.

É importante destacar que pelas condições da área e principalmente do ano de condução do presente experimento com precipitações maiores que $\mathrm{o}$ normal (Tabela 1) na estação seca, que a pastagem apresentou percentual relativamente alto dos componentes verdes $(48,63 \%)$, o que provavelmente influenciou positivamente no desempenho animal obtido nas estratégias de suplementação.

No ganho de peso médio diário não houve interação $(\mathrm{P}=0,52)$ entre tratamento e período. O GMD dos novilhos diminuiu de 0,547 para $0,298 \mathrm{~kg}$ do primeiro (agosto) ao terceiro (outubro) período na média dos tratamentos, sendo explicado em grande parte pelas alterações na massa de forragem ao longo da seca em função das condições ambientais (Tabela 1).

A SC proporcionou GMD de $0,562 \mathrm{~kg}$ (Tabela 2), superior ao obtido por Baroni et al. (2010) com suplementação de novilhos nelore em terminação na seca, que obtiveram $0,320 \mathrm{~kg} / \mathrm{dia}$ com fornecimento de $0,43 \%$ PC e similar aos resultados de Goes et al. (2005) que obtiveram ganhos de $0,600 \mathrm{~kg} / \mathrm{dia}$ no nível de concentrado de $0,5 \%$ PC em período seco.
Os animais suplementados com SMP obtiveram GMD de $0,395 \mathrm{~kg}$, valores superiores aos obtidos por Moreira et al. (2004) com ganho de $0,200 \mathrm{~kg} / \mathrm{dia}$ e Baroni et al. (2010) consumindo 0,250kg de suplemento proteico com desempenho de $0,257 \mathrm{~kg} / \mathrm{dia}$, ambos com novilhos Nelore. Domingues et al. (2009) realizaram avaliação econômica do presente experimento, os quais obtiveram menor custo e maior lucratividade para a suplementação com o sal proteinado em relação ao concentrado. Também, estes últimos autores afirmaram que mesmo com ganho médio diário menor, a utilização do sal mineral proteinado de "alto consumo" é uma alternativa interessante, principalmente para as propriedades que têm limitações de estrutura, anos com menor intensidade de seca, além de reduzir os custos da suplementação.

Os novilhos submetidos a SC apresentaram maior espessura de gordura subcutânea ajustada para $100 \mathrm{~kg}$ de carcaça $(\mathrm{P}<0,01)$ que os suplementados com SMP, entretanto, não se observaram diferença $(\mathrm{P}>0,01)$ para o peso de carcaça, rendimento de carcaça, área de olho de lombo e área de olho de lombo ajustada (Tabela 3).

Tabela 3. Características de carcaça de bovinos da raça Nelore suplementados no período seco com sal mineral proteinado e concentrado

\begin{tabular}{lcc}
\hline Características & Sal mineral proteinado & Suplementação com concentrado \\
\hline Peso de carcaça $(\mathrm{kg})$ & $265^{\mathrm{a}}$ & $259^{\mathrm{a}}$ \\
Peso de abate $(\mathrm{kg})$ & $493^{\mathrm{a}}$ & $483^{\mathrm{a}}$ \\
Dias para abate & $205^{\mathrm{a}}$ & $123^{\mathrm{b}}$ \\
Rendimento de carcaça (\%) & $53,75^{\mathrm{a}}$ & $53,62^{\mathrm{a}}$ \\
EGS (mm) & $3,4^{\mathrm{a}}$ & $4,4^{\mathrm{a}}$ \\
EGS ajustada para 100kg de carcaça (mm) & $1,3^{\mathrm{b}}$ & $1,7^{\mathrm{a}}$ \\
AOL (cm $\left.{ }^{2}\right)$ & $66,2^{\mathrm{a}}$ & $69,0^{\mathrm{a}}$ \\
AOL ajustada para 100kg de carcaça $\left(\mathrm{cm}^{2}\right)$ & $24,9^{\mathrm{a}}$ & $26,8^{\mathrm{a}}$ \\
pH & $5,40^{\mathrm{a}}$ & $5,38^{\mathrm{a}}$ \\
Marmorização & $3,2^{\mathrm{a}}$ & $3,2^{\mathrm{a}}$ \\
\hline
\end{tabular}

EGS = espessura de gordura subcutânea, AOL = área de olho de lombo.

Médias seguidas de letras minúsculas distintas, na linha, diferem entre si pelo teste $\mathrm{F}(\mathrm{P}<0,01)$. 
Apesar dos animais que consumiram SC apresentarem maior ganho de peso que os animais suplementados com SMP, os pesos de abate, de carcaça e o rendimento de carcaça não exibiram diferenças significativas, isso é explicado porque os animais dos dois tratamentos foram abatidos com pesos similares e existe alta correlação entre peso de abate e rendimento de carcaça. Os animais da SC tiveram maior ganho de peso e foram abatidos antes (123 dias do início do experimento) e os animais suplementados com SMP foram abatidos 82 dias depois (com 123 dias de suplementação mais 82 dias em pastagem somente com suplementação mineral), já que com ganho de peso menor necessitaram mais tempo no pasto para atingir o peso de abate.

A espessura de gordura subcutânea é considerada uma avaliação quantitativa da carcaça e está positivamente relacionada com a quantidade de gordura total e negativamente com a percentagem de cortes desossados, afeta também a velocidade de resfriamento da carcaça, comportando-se como um eficiente isolante térmico, sendo que, a indústria frigorífica exige cobertura de gordura de 3 a $6 \mathrm{~mm}$.

Os valores desta característica observados para os dois tratamentos (Tabela 3) atenderam a estes limites, porém não diferiram estatisticamente entre as estratégias de suplementação e estão dentro dos parâmetros exigidos pela indústria frigorífica. Já a espessura de gordura subcutânea ajustada foi maior para a suplementação concentrada, em virtude do maior aporte energético que favoreceu a deposição de gordura subcutânea.

Segundo Luchiari Filho (2000), a espessura de gordura ajustada deve ficar em torno de 2 a $2,5 \mathrm{~mm} / 100 \mathrm{~kg}$ de carcaça, se quisermos manter uma mesma proporção de gordura de cobertura, tanto na carcaça leve como na pesada. Nos dois tratamentos (Tabela 3), as médias foram inferiores ao parâmetro citado por Luchiari Filho (2000), sendo que a SC apresentou o valor mais próximo a $2 \mathrm{~mm} / 100 \mathrm{~kg}$ de carcaça, mantendo a proporção de gordura na carcaça mais próxima ao ideal.

Em bovinos, a AOL ajustada para $100 \mathrm{~kg}$ de peso de carcaça deve ser no mínimo $29 \mathrm{~cm}^{2} / 100 \mathrm{~kg}$ de carcaça, o que é um indicativo de bom rendimento de cortes (LUCHIARI FILHO, 2000), nos dois tratamentos os animais não atingiram o valor mínimo indicado, mostrando que os animais poderiam apresentar melhor desenvolvimento muscular.

A AOL ajustada para $100 \mathrm{~kg}$ de carcaça (Tabela 3) foi similar à obtida por Polizel Neto et al. (2009) que obtiveram $26,66 \mathrm{~cm}^{2}$ em novilhos Nelore suplementados com sal mineral proteinado na seca.

Em relação às características qualitativas da carne, não houve diferença $(\mathrm{P}>0,01)$ entre os valores de $\mathrm{pH}$ da carne de animais da SC $(5,38)$ e SMP $(5,40)$. De acordo com Fernandes et al. (2008) o pH 6,0 é considerado como um divisor entre o corte normal e $o$ dark-cutting, e no Brasil os frigoríficos exportam apenas a carne que apresenta $\mathrm{pH}$ abaixo de 5,80, avaliando diretamente no músculo Longissimus, 24 horas post-mortem. Os valores médios de $\mathrm{pH}$ (Tabela 3) indicam que os animais receberam manejo correto antes e durante o abate, uma vez que os valores dessa variável foram condizentes ao preconizado pela literatura mostrando que a carne está boa para o consumo, processamento e exportação.

Em relação à marmorização, não houve diferença entre as suplementações mostrando que a densidade energética 
Rev. Bras. Saúde Prod. Anim., Salvador, v.15, n.4, p.1052-1060 out./dez., 2014 http://www.rbspa.ufba.br ISSN 15199940

maior da dieta com concentrado não foi suficiente para promover maior a deposição de gordura intramuscular e também porque animais zebuínos apresentam menor marmorização. Nos tratamentos, o escore de marmorização foi 3,2 (Tabela 3), ou seja, escore leve, corroborando com Moreira et al. (2003) que, trabalhando com novilhos Nelore suplementados com sal mineral proteinado e terminados em pastagem, obtiveram escore de marmorização leve.

A suplementação com concentrado durante o período seco proporciona maior ganho de peso médio diário e espessura de gordura subcutânea ajustada para $100 \mathrm{~kg}$ de carcaça, antecipando a idade de abate.

A utilização de sal mineral proteinado com massa de forragem adequada pode ser uma alternativa de suplementação devido menor exigência de estrutura, controle de consumo, menor mão-deobra e maior facilidade no fornecimento.

\section{REFERÊNCIAS}

BARONI, C.E.S.; LANA, R.P.; MANCIO, A.B.; QUEIROZ, A.C.; SVERZUT, C.B.; MENDONÇA, B.P.C. Desempenho de novilhos suplementados e terminados em pasto, na seca, e avaliação do pasto. Arquivo Brasileiro de Medicina Veterinária e Zootecnia, v.62, n.2, p.373-381, 2010.

BARONI, C.E.S.; LANA, R.P.; MANCIO, A.B.; QUEIROZ, A.C.; LEÃO, M.I.; SVERZUT, C.B. Níveis de suplemento à base de fubá de milho para novilhos Nelore terminados a pasto na seca: desempenho, características de carcaça e avaliação do pasto. Revista
Brasileira de Zootecnia, v.39, n.1, p.175-182, 2010.

DOMINGUES, M.S.; LUPATINI, G.C.; MEDEIROS, S.F.; SABBAG, O.J.; LOLI, A.; ANDRIGHETTO, C.; ARAÚJO, L.C.A. Avaliação econômica da terminação de bovinos de corte em pastagem diferida de Brachiaria brizantha submetidos à suplementação com sal mineral proteinado ou concentrada. In: SIMPÓSIO DE CIÊNCIAS DA UNESP DE DRACENA, 5., 2009, Dracena. Anais... Dracena: Universidade Estadual Paulista, 2009.

EUCLIDES, V.P.B.; FLORES, R.; MEDEIROS, R.N.; OLIVEIRA, M.P. Diferimento de pastos de braquiária cultivares Basilisk e Marandu, na região do Cerrado. Pesquisa Agropecuária Brasileira, v.42, n.2, p.273-280, 2007.

FERNANDES, A.R.M.; SAMPAIO, A.A.M.; HENRIQUE, W.; OLIVEIRA, E.A.; TULLIO, R.R.; PERECIN, D. Características da carcaça e da carne de bovinos sob diferentes dietas, em confinamento. Arquivo Brasileiro de Medicina Veterinária e Zootecnia, v.60, n.1, p.139-147, 2008.

FERNANDES, L.O.; REIS, R.A.; PAES, J.M.V. Efeito da suplementação no desempenho de bovinos de corte em pastagem de Brachiaria brizantha cv. Marandu. Ciência e Agrotecnologia, v.34, n.1, p.240-248, 2010.

GOES, R.H.T.B.; MANCIO, A.B.; LANA, R.P.; ALVES, D.D.; LEÃO, M.I.; SILVA, A.T.S. Recria de novilhos mestiços em pastagens de Brachiaria brizantha, com diferentes níveis de suplementação, na região amazônica. Desempenho animal. Revista

Brasileira de Zootecnia, v.34, n.5, p.1740-1750, 2005. 
Rev. Bras. Saúde Prod. Anim., Salvador, v.15, n.4, p.1052-1060 out./dez., 2014 http://www.rbspa.ufba.br ISSN 15199940

LANA, R.P. Nutrição e alimentação

animal: mitos e realidades. 2.ed.

Viçosa: Universidade Federal de

Viçosa, 2007. 344p.

LUCHIARI FILHO, A. Pecuária da

carne bovina. 1.ed. São Paulo, 2000. $134 \mathrm{p}$.

MORAES, E.H.B.K.; PAULINO, M.F.; ZERVOUDAKIS, J.T.; VALADARES

FILHO, S.C.; CABRAL, L.S.;

DETMANN, E.; VALADARES,

R.F.D.; MORAES, K.A.K. Associação

de diferentes fontes energéticas e

proteicas em suplementos múltiplos na recria de novilhos mestiços sob pastejo no período da seca. Revista Brasileira de Zootecnia, v.35, p.914-920, 2006.

MOREIRA, F.B.; PRADO, I.N.; CECATO, U.; ZEOULA, L.M.; WADA, F.Y.; TORII, M.S. Níveis de suplementação com sal mineral proteinado para novilhos Nelore terminados em pastagem no período de baixa produção forrageira. Revista Brasileira de Zootecnia, v.33, n.6, p.1814-1821, 2004. Supl. 1.

MOREIRA, F.B.; SOUZA, N.E.; MATSUSHITA, M.; PRADO, I.N.; NASCIMENTO, W.G. Evaluation of carcass characteristics and meat chemical composition of Bos indicus and Bos indicus x Bos taurus crossbred steers finished in pasture systems. Brazilian Archives of Biology and Technology, v.46, n.4, p.609-616, 2003.

MOREIRA, L.M.; SANTOS, M.E.R.; FONSECA, D.M.; MARTUSCELLO, J.A.; MORAIS, R.V.; MISTURA, C. Produção animal em pastagem de capim-braquiária adubada com nitrogênio. Arquivo Brasileiro de Medicina Veterinária e Zootecnia, v.63, n.4, p.914-921, 2011.
OLIVEIRA, L.O.F.; SALIBA, E.O.S.; GONÇALVES, L.C.; BORGES, I.;

MIRANDA, P.A.B.; FIALHO, M.P.F.

Digestibilidade in situ e cinética ruminal de bovinos de corte a pasto sob suplementação com proteinados.

Revista Brasileira de Zootecnia, v.39, n.6, p.1328-1335, 2010.

POLIZEL NETO, A.; JORGE, A.M.; MOREIRA, P.S.A.; GOMES, H.F.B.; PINHEIRO, R.S.B. Desempenho e qualidade da carne de bovinos Nelore e F1 Brangus $\times$ Nelore recebendo suplemento com cromo complexado à molécula orgânica na terminação a pasto. Revista Brasileira de Zootecnia, v.38, n.4, p.737-745, 2009.

SILVA, F.F.; SÁ, J.F.; SCHIO, A.R.; ÍTAVO, L.C.V.; SILVA, R.R.; MATEUS, R.G. Suplementação a pasto: disponibilidade e qualidade $\mathrm{x}$ níveis de suplementação x desempenho. Revista Brasileira de Zootecnia, v.38, p.371389, 2009. Supl. especial.

UNITED STATES DEPARTMENT OF AGRICULTURE -USDA. United states standards for grades of carcass beef. Washington: Livestock and Seed Division, 1997. 16p.

Data de recebimento: 27/08/2014

Data de aprovação: 26/11/2014 